\title{
The Accuracy-Confidence Correlation in Eyewitness Testimony: Limits and Extensions of the Retrospective Self-Awareness Effect
}

\author{
Saul M. Kassin \\ Williams College
}

\author{
Scott Rigby \\ University of Rochester
}

\author{
Sylvia R. Castillo \\ Williams College
}

\begin{abstract}
This research extended Kassin's (1985) finding that retrospective self-awareness (RSA) increases the correlation between eyewitness accuracy and confidence. In Experiment 1,91 mock witnesses saw a crime, answered questions, madc an identification decision, and rated their confidence. RSA increased the accuracy-confidence correlation for witnesses who made an identification and for those who were high but not low in public self-consciousness. A 2nd experiment varied accountability and revealed that high accountability increased the accuracy-confidence correlation but that the RSA effect occurred even under low-accountability conditions. In both studies, observers could not distinguish between accurate and inaccurate witnesses. Together, these findings define the limits of the RSA effect and provide mixed support for a self-perception account of this effect.
\end{abstract}

Among college students, jurors, police officers, trial lawyers, and even the U.S. Supreme Court, it is believed that eyewitness identification accuracy and confidence are highly correlated (Brigham \& Wolfskiel, 1983; Deffenbacher \& Loftus, 1982; Manson v. Brathwaite, 1977; Neil v. Biggers, 1972; Yarmey \& Jones, 1983). Despite the allure of common sense, however, research indicates that eyewitness confidence does not reliably predict identification accuracy either between subjects (Bothwell, Deffenbacher, \& Brigham, 1987; Wells \& Murray, 1984) or within subjects (Smith, Kassin, \& Ellsworth, 1989). Thus, in a recent survey of expert opinion, a vast majority of eyewitness experts agreed that accuracy and confidence are not reliably correlated (Kassin, Ellsworth, \& Smith, 1989).

Consistent with Wells's (1978) distinction between estimator variables (factors that cannot be controlled a priori but can be used to estimate the accuracy of an eyewitness report, e.g., the stressfulness of an observed event) and system variables (factors that can be controlled within the criminal justice system, e.g., lineup identification procedures), two remedial approaches can be taken. The first is to inform legal decision makers about the lack of association between accuracy and confidence, leaving them to focus on the conditions under which witnesses acquire, store, and retrieve their observations. Indeed, mock jury research suggests that although jurors rely heavily on confidence-related cues (Cutler, Penrod, \& Stuve, 1988), expert tes-

The research reported in this article was submitted as an honor's thesis by Scott Rigby to the Department of Psychology, Williams College, and was supported through discretionary funds provided by the Bronfman Science Center to Saul M. Kassin.

We thank David Dunning, who provided stimulus materials, and Carol Suzuki, who served as the experimenter for the Stanford University study cited in our discussion.

Correspondence concerning this article should be addressed to Saul M. Kassin, Department of Psychology, Bronfman Science Center, Williams College, Williamstown, Massachusetts 01267. timony can lead them to use more diagnostic information (Cutler, Penrod, \& Dexter, 1989). A second approach is to increase the actual accuracy-confidence correlation so that common sense would serve decision makers well. The present research was designed with this latter goal in mind.

In an earlier article, Kassin (1985) proposed that the lack of correlation between accuracy and confidence is a problem in self-perception and subjective self-report. In a series of studies, subjects saw a staged crime, tried to identify the culprit from a photographic lineup, and then rated their confidence in the identification. In addition, some subjects were assigned to a retrospective self-awareness (RSA) condition in which they saw a videotape of themselves making an identification decision before rating their level of self-confidence. The overall correlation between identification accuracy and confidence was nonsignificant among subjects in the control conditions, including a camera-present group in which subjects knew they were being videotaped but then received no exposure to the tape $(r=.04$, $n=126$ ). Among those in the RSA condition, however, the correlation was highly significant $(r=.48, p<.001, n=102)$.

Two possible explanations for the RSA effect were proposed. One is that videotaped self-exposure serves to alert witnesses to informative but previously unobserved mannerisms or variations in their overt behavior (e.g., response time, verbal utterances, facial expressions, and other nonverbal cues). This selfperception hypothesis implies that videotape feedback provides actors with information otherwise available to an outside observer. A second possibility is that videotaped feedback enables subjects to more readily access the thought processes accompanying their original performance. As suggested by this retrieval-cue hypothesis, actors are privileged with private selfknowledge that can be retrieved by the experience of retrospective self-awareness.

Kassin's (1985) studies offered some degree of support for the self-perception account. For example, subjects who were high 
in their dispositional levels of public self-consciousness (i.e., those who were attentive to their own appearance and behavior as seen by others) benefited the most from the RSA procedure, and observers who watched the identification tapes ascribed higher levels of confidence to witnesses who were correct rather than incorrect in their identifications. In contrast, the retrievalcue hypothesis received virtually no support. Subjects who were high in their dispositional levels of private self-consciousness (i.e., those who reflected on their inner thoughts and feelings) derived the least benefit from the RSA procedure, and efforts to enhance subjects' introspective tendencies failed to increase the accuracy-confidence correlation. In both trait and state terms, then, the RSA effect was obtained with subjects who were focused on overt behavioral cues but not with those who were focused on their own thought processes.

\section{Experiment 1}

We designed this research with three objectives in mind. First, we sought to replicate Kassin's (1985) results using different stimulus materials and including blank lineups in which the offender was absent. In a valid offender-present lineup, a correct decision consists of identifying the culprit (hits), and errors consist of choosing an innocent suspect (false alarms) or no suspect at all (misses). In a blank lineup, nonidentification is the correct decision for subjects to make, because all lineup choices are innocent. Eyewitness research has shown that the accuracy-confidence correlation is influenced by the type of lineup and the manner of its presentation (Cutler \& Penrod, 1988; Lindsay \& Wells, 1985; Malpass \& Devine, 1984; Melara, DeWitt-Rickards, \& O’Brien, 1989; Wells \& Lindsay, 1985). For example, it appears that the accuracy-confidence correlation is higher among subjects who make an identification than among those who do not (Fleet, Brigham, \& Bothwell, 1987; Kassin, 1985). We sought to examine whether these factors moderate the RSA effect.

Second, we explored possible self-perception and retrievalcue mechanisms underlying the RSA effect. From an individual differences perspective, we retested an implication of the self-perception hypothesis: that videotaped self-exposure increases the accuracy-confidence correlation most among subjects who are high in their dispositional levels of public rather than private self-consciousness. We also developed a more sensitive test of the retrieval-cue hypothesis. Previously, RSA subjects observed themselves from a frontal position, a camera angle that prompts attention to such cues as facial expression and other witness behaviors. To enable subjects to recall more effectively the subjective experience of making their decisions, we developed an RSA manipulation that reinstated their original perspective on the stimulus. Thus, we included an over-theshoulder RSA group in which the camera was focused on the photographic lineup during the identification.

Third, we sought to determine whether observers such as jurors could more accurately evaluate eyewitness testimony by observing videotapes of the identification process. Research indicates that people have difficulty distinguishing between accurate and inaccurate witnesses on the basis of courtroom testimony, in part because they rely heavily on confidence cues (Lindsay, Wells, \& O'Connor, 1989; Lindsay, Wells, \& Rumpel,
1981; Wells, Lindsay, \& Ferguson, 1979). To examine whether performance is improved by exposure to RSA tapes, observers evaluated witnesses after watching tapes of their examinations, the identification decisions, or both.

\section{Method}

\section{Phase 1: Witnesses}

Subjects and design. Ninety-six students ( 37 men and 59 women) participated as mock witnesses in exchange for either course credit or money. Of these, 76 subjects were randomly assigned to participate in either an RSA or a control group and to evaluate either an offender-present or an offender-absent lineup. An additional 20 subjects took part in an over-the-shoulder RSA group in which the offender was always present in the lineup.' All subjects were classified, by median splits, as high or low on measures of private and public self-consciousness.

Stimulus event. All subjects watched a color videotape of a staged crime that lasted for $28 \mathrm{~s}$. The event was recorded from behind a cafeteria-style snack table in a lounge. Several students walked by. At one point, a college-age woman came in, set down her purse, and reached for an item on the table. From behind, a young White man approached the table and grabbed the purse. A struggle ensued and the victim screamed for help, but the thief wrestled the purse from her and ran out of the room.

Procedure. Subjects participated individually in sessions that lasted approximately $40 \mathrm{~min}$. On their arrival, subjects were told only that they would view an "interpersonal event" about which they would be questioned. After watching the crime tape, subjects were seated on the witness stand in a mock courtroom and asked 19 questions, some open-ended (e.g., "Describe what happened.") and others more specific (e.g., "What color was the thief's hair?"). Stationed on a tripod $10 \mathrm{ft}$ $(3.05 \mathrm{~m})$ away, a video camera recorded the entire examination.

After this examination was complete, subjects were presented with a photo spread that consisted of six 4 in. $\times 6$ in. $(10.16 \mathrm{~cm} \times 15.24 \mathrm{~cm})$ color portrait photographs labeled $a$ through $f$. Each of the six photographs was mounted on a separate page in a looseleaf notebook. For subjects in the offender-present lineup condition, the thief appeared in Position c; for those in the offender-absent condition, his photo was replaced by a sixth foil, similar in appearance (similarity was subjectively determined; the foil was roughly the same age and had a similar complexion, hairstyle and color, and dark eyes). All subjects were instructed that "the thief may or may not be in this group of photographs. Look through them. If you think he is in there, point to the picture and state the letter $(a-f)$ that corresponds to it." Subjects were thus asked to examine all the photographs, to decide if the thief was present, and if so, to make a selection. ${ }^{2}$ In both the RSA and control groups, the subjects were videotaped head-on as they examined the photographs and made a decision. In the over-the-shoulder RSA group, the camera recorded the lineup from above and behind the witness's left shoulder. All subjects were told they were being videotaped.

After their identification decision, subjects completed a small packet of questionnaires, including the Self-Consciousness Scale (Fen-

\footnotetext{
' Initially, only 15 subjects were assigned to the over-the-shoulder group. For a more powerful test of the retrieval-cue hypothesis, 5 subjects were later added to this condition.

2 "I don't know" was not a response option. Subjects either made a choice or decided that the culprit was not in the lineup.
} 
igstein, Scheier, \& Buss, 1975). ${ }^{3}$ Subjects in the RSA groups then watched the videotape of their identification before making their confidence ratings. Those in the control group were asked after $2 \mathrm{~min}$ to rate their confidence in the accuracy of their identification decisions on a 10-point scale ranging from not at all confident (1) to very confident (10). As soon as the confidence data were obtained, subjects were debriefed and thanked for their participation.

\section{Phase 2: Observers}

Subjects and design. Sixty students ( 31 men and 29 women) were randomly assigned to onc of three observer groups ( $n=20$ per group), and all subjects watched one witness. Subjects in an examination-only group watched a videotape of the questioning of one eycwitness. Those in an identification-only group watched a videotape of the witness searching through the photographs and making an identification decision. Subjects in the third group watched both the examination and the identification procedures.

Procedure. Twenty witnesses- 10 accurate in their identifications, 10 inaccurate-were randomly selected from the first part of the experiment. For each witness, observers saw the examination videotape, the identification videotape, or both. They were instructed as follows:

The videotape I'm going to show you is of a person who witnessed a crime. After being asked a series of questions, the eyewitness was given an opportunity to identify the criminal from a group of photographs. As you watch, please think of yourself as a juror watching eyewitness testimony in a courtroom.

After viewing a videotape, subjects completed a questionnaire in which they rated the accuracy and completeness of the witness's testimony, judged whether the witness had made an accurate identification, rated their confidence in that judgment, and estimated the witness's level of confidence. All ratings were made on a 1- to 10-point scale.

\section{Results}

\section{Phase 1: Witnesses}

Of the 76 subjects who participated as witnesses in the 2 (RSA, control) $\times 2$ (offender present, absent) design, $55(72.4 \%$ ) made an identification, and 21 (27.6\%) did not. Among those who did, $19(34.5 \%)$ were accurate, and $36(65.5 \%)$ were not. Among those not making an identification, $12(57.1 \%)$ were accurate (in the offender-absent lineup), and 9 (42.9\%) were not (in the offender-present lineup). In the over-the-shoulder group, to be discussed later, 9 subjects made an accurate identification, 7 made an incorrect choice, and 4 made an incorrect nonchoice. The identification data for all groups are presented in Table 1 .

Table 1

Identification Decisions in Each Condition

\begin{tabular}{lrrrc}
\hline \multicolumn{1}{c}{ Condition } & RSA & Control & Total & Over-the-shoulder \\
\hline Offender present & & & & \\
$\quad$ Correct choice & 10 & 9 & 19 & 9 \\
$\quad$ Incorrect choice & 6 & 6 & 12 & 7 \\
$\quad$ Incorrect nonchoice & 4 & 5 & 9 & 4 \\
Offender absent & 13 & 11 & 24 & - \\
Incorrect choice & 7 & 5 & 12 & - \\
Correct nonchoice & & 36 & 76 & 20 \\
$\quad$ Total & 40 & &
\end{tabular}

Note. $\quad \mathrm{RSA}=$ retrospective self-awareness.
Across subjects in the four main groups, the mean confidence rating was 4.42 , and the mean response time was $46.81 \mathrm{~s}$. As in previous research, identification accuracy and confidence were not significantly correlated $\left(r_{\mathrm{pb}}=.20, p<.10, n=\right.$ 76). Consistent with data reported by Kassin (1985) and Sporer (1990), there were significant but modest negative correlations between accuracy and response latency $(r=-.22, p<.05, n=$ 76) and between response latency and confidence $(r=-.25, p<$ $.02, n=76$ ).

Between-groups analyses indicated that neither the RSA nor the lineup factor significantly affected identification accuracy, $\chi^{2} \mathrm{~s}(1, N=76)=1.57$ and .10 , respectively, or response latency (both $F \mathrm{~S}<1$ ). Analysis of variance (ANOVA) on confidence ratings, however, revealed that confidence was higher among subjects in the offender-present condition than in the offenderabsent condition ( $M \mathrm{~s}=4.9$ and 3.9 , respectively), $F(1,72)=$ $4.53, p<.05$. To examine variations in the correlation between accuracy and confidence, the two lineup conditions were combined for analysis. Accurate identification responses thus consisted of correct choices in the offender-present lineup plus correct nonchoices (refusals to make an identification) in the offender-absent lineup. Inaccurate responses consisted of incorrect choices (false identifications) in both lineups plus incorrect nonchoices in the offender-present lineup. To test the hypothesis that RSA increases the accuracy-confidence correlation and to examine the roles of public and private self-consciousness, accuracy was included as a factor in two 2 (RSA, control) $\times 2$ (high, low self-consciousness) $\times 2$ (accurate, inaccurate identification) factorial ANOVAs (one for public and one for private self-consciousness), with confidence as the dependent variable.

In the analysis that included public self-consciousness as a factor, neither the main effect for identification accuracy nor the Accuracy $\times$ RSA interaction was significant. A significant three-way interaction, however, indicated that accurate witnesses exhibited higher levels of confidence than inaccurate witnesses only when they were high in public self-consciousness and were in the RSA condition, $F(1,68)=8.24, p<.005$ (see Figure 1). Expressed in correlational terms, accuracy and confidence were highly and significantly correlated in this cell $\left(r_{\mathrm{pb}}=\right.$ $.52, p<.01, n=24$ ), but not in any of the others. In contrast to the moderating role played by public self-consciousness, a second $2 \times 2 \times 2$ ANOVA indicated that private self-consciousness had no effect on confidence ratings either alone or in interaction with other factors. As in prior research (Fenigstein et al., 1975), public and private self-consciousness scores were moderately correlated $(r=.23, p<.01, n-76)$.

Because Kassin (1985) found a greater RSA effect among subject witnesses who chose a photograph than among those who did not, we reanalyzed our data for the subsample of witnesses who made accurate versus inaccurate identifications. The results revealed the same pattern: The accuracy-confdence correlation among choosers was significant in the RSA condition $\left(r_{\mathrm{pb}}=.43, p<.02, n=29\right)$, but not in the control group $(r=.22, n=26)$. Yet among nonchoosers (subjects who correctly

\footnotetext{
${ }^{3}$ Subjects filled out the Need for Cognition Scale (Cacioppo \& Petty, 1982) and the Self-Monitoring Scale (Snyder \& Gangestad, 1986), although neither measure moderated the accuracy-confidence correlation.
} 


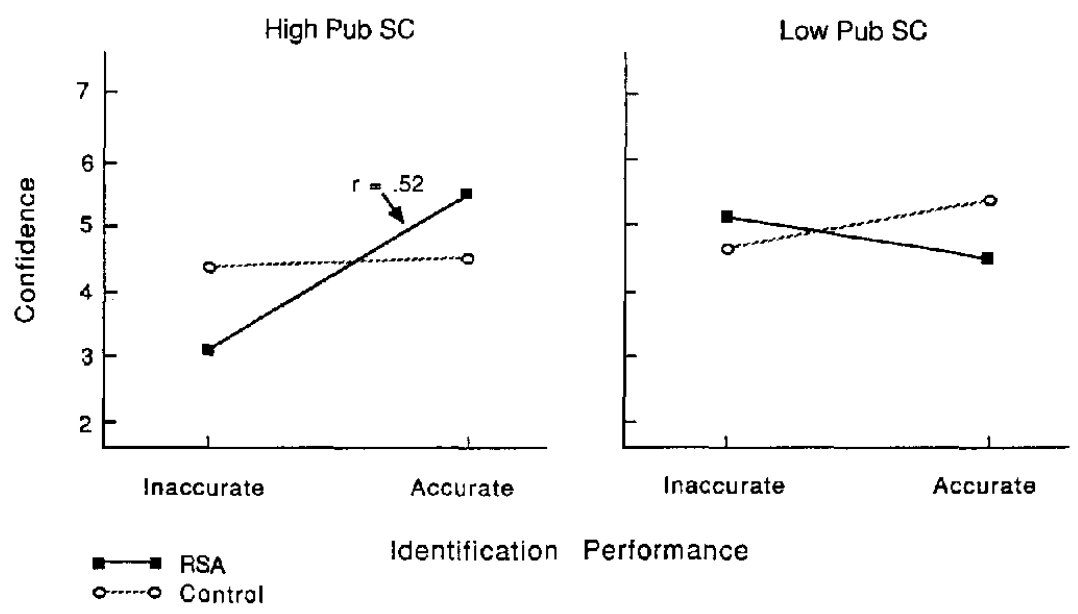

Figure 1. Confidence ratings as a function of retrospective self-awareness (RSA), public self-consciousness (Pub SC), and identification accuracy.

or incorrectly did not make an identification), the correlation was not significant in either the RSA or the control group ( $r=$ $-.22, n=11$, and $r=.15, n=10$, respectively).

Twenty subjects participated in an RSA procedure in which they viewed an over-the-shoulder videotape of the photo spread recorded as they examined the photographs and made their decisions. This procedure was designed for a more potent test of the retrieval-cue hypothesis. However, the accuracy-confidence correlation in this group - somewhat higher among subjects who were high rather than low on public self-consciousness $\left(r_{\mathrm{pb}} \mathrm{s}=.28\right.$ and -.06 , based on $n \mathrm{~s}$ of 9 and 11 , respectively)was not significant overall $(r=.16, n=20)$ or for the subsample of choosers $\left(r_{\mathrm{pb}}=.27, n=16\right)$. For all other subjects who viewed an offender-present lineup, the comparable correlations were .43 in the RSA group and .20 in the control group $(n=20$ in both cells).

\section{Phase 2: Observers}

Overall, $42 \%$ of observers evaluated the witness they saw as accurate in his or her identification decision. These judgments were not affected by whether subjects viewed an examination, an identification, or both, $\chi^{2}(2, N=60)<1$. There was, however, a significant effect on estimates of witness confidence, $F(1$, $58)=4.25, p<.05$. Subjects who watched an identification videotape alone or in combination with the examination rated witness confidence as lower ( $M S=4.45$ and 4.65 , respectively) than those who watched an examination videotape only $(M=$ $5.83)$. For subjects who saw the identification process, ratings of witness confidence increased as response latencies decreased $(r=-.33, p<.05, n=40$ ). This correlation was found among witnesses as well, and it suggests that subjects may have used decision-making time to infer witness confidence.

Looking at the correlations between the various judgments proved interesting. First, there was a significant correlation between observer perceptions of witness accuracy and confidence: Witnesses judged accurate were also perceived as more confident than those judged inaccurate $\left(r_{\mathrm{pb}}=.47, p<.001, n=\right.$ 60 ). This result is consistent with previous research showing that people believe as a matter of common sense that these two variables covary (Deffenbacher \& Loftus, 1982; Wells et al., 1979; Yarmey \& Jones, 1983). Second, observer estimates of identification accuracy were significantly correlated with their ratings of how correctly and how completely the witness could remember other details of the staged crime $\left(r_{\mathrm{pb}}=.28, p<.05\right.$, and $r=.35, p<.01$, respectively; $n s=60$ ). These data are consistent with studies showing that people infer identification accuracy from a witness's memory for peripheral, even trivial details (Bell \& Loftus, 1989; Deffenbacher \& Loftus, 1982). In actuality, identification accuracy and memory test scores were not significantly correlated among our witnesses $\left(r_{\mathrm{pb}}=-.07, n=\right.$ 96). As in other research (Cutler, Penrod, \& Martens, 1987; Wells \& Leippe, 1981), however, the correlation was in a negative direction.

The main question we addressed was whether observers could better determine a witness's level of confidence, or accuracy, by observing a videotape of the identification decision. Although a self-perception account implies they could, the data indicated they could not. Across all groups, observer ratings of witness confidence were significantly correlated with witness self-ratings of confidence $(r=.26, p<.05, n=60)$. But there were no significant differences between groups. As to whether jurors could discriminate better between accurate and inaccurate witnesses by watching the identification process, the results were not supportive. Out of the 60 observers, $33(55 \%)$ were correct and $27(45 \%)$ were incorrect in their judgments of lineup identifications, discriminations that did not exceed chance performance. (Interestingly, juror accuracy and confidence were uncorrelated, $r_{\mathrm{pb}}=.02, n=60$.) Again, there were no betweengroups differences.

\section{Experiment 2}

Experiment 1 replicated the RSA effect among subjects who made correct versus incorrect identifications, but not among those who correctly or incorrectly chose not to make an identification. The results provided no support for the retrieval-cue hypothesis, as indicated by the failure of the over-the-shoulder 
camera angle to produce a significant accuracy-confidence correlation and by the failure to find significant differences on the measure of private self-consciousness. There was, however, mixed support for a self-perception account of the RSA effect. On the positive side, subjects who were high in public selfconsciousness clearly benefited from videotaped self-exposure, as they exhibited a significant accuracy-confidence correlation in the RSA condition. On the negative side, observers who viewed the actual identification tapes were not more accurate in their judgments of the witnesses than those who viewed only the witness's examination.

In light of these results-replicating the RSA effect but providing no support for the retrieval-cue hypothesis and only mixed support for the self-perception hypothesis-a second experiment was designed to test a third possible explanation for our findings, one based on the mechanism of accountability. Research indicates that accountability motivates people to process information in more careful, self-critical ways. When people feel accountable for decisions, they process information in greater detail, pay more attention to inconsistencies, form more complex impressions, and are less prone to social-cognitive biases such as primacy (Tetlock, 1983) and the fundamental attribution error (Tetlock, 1985). Particularly relevant to our research, Tetlock and $\mathrm{Kim}(1987)$ found that in contrast to the overconfidence bias often found in social judgment (Dunning, Griffin, Milojkovic, \& Ross, 1990), subjects in whom accountability concerns were heightened before engaging in a task subsequently reported more appropriate levels of confidence in their own judgments (also see Sharp, Cutler, \& Penrod, 1988).

In the context of our paradigm, a possible explanation for the RSA effect is that the processes of videotaping and self-exposure-by enhancing the public nature of the witness's task and arousing evaluation apprehension-lead subjects to feel more accountable for their confidence reports, thus motivating them to think more carefully about their task performance. ${ }^{4}$ To test this hypothesis, RSA and accountability were independently varied. As in Experiment 1, subjects watched a crime, made an identification decision, and rated their confidence with or without videotaped self-exposure. In addition, half of the subjects in each condition received a high-accountability instruction and half received a low-accountability instruction. Two questions were asked: (a) Is accountability necessary for the RSA effect to occur (i.e., is the accuracy-confidence correlation diminished in a low-accountability RSA situation)? and (b) is accountability a sufficient condition for the RSA effect to occur (i.e., is there a significant correlation in a high-accountability control situation)?

To further explore an implication of the self-perception account--specifically, whether the witness identification videotapes contained overt behavioral information useful to others -we also had close friends of a sample of witnesses observe the tapes and evaluate their friend's accuracy and confidence. Even though strangers seem unable to derive from these tapes confidence estimates that correlate with identification accuracy, perhaps the observer hypothesis should be modified, limited to those who know a witness well enough to decode the available information. Indeed, recent evidence suggests that people are generally more accurate when they assess the personality of their friends than of strangers they meet in a laboratory (Funder \& Colvin, 1988).

\section{Method}

\section{Subjects and Design}

Participating in exchange for course credit or money, 65 students ( 38 men and 27 women) were randomly assigned to one of the four cells produced by a 2 (RSA, control) $\times 2$ (high, low accountability) factorial design. An additional 19 subjects ( 7 men and 12 women) were later recruited by phone and paid to take part as observers. Each was the close friend of a witness and was selected randomly among the 65 witnesses, subject to availability and our desire to sample from an equal number of correct and incorrect choosers.

\section{Procedure}

The procedure was nearly identical to that of the first study, except for the inclusion of accountability instructions and manipulation checks, the use of a much shorter (i.e., two brief and perfunctory questions) examination, and the use of a hidden camera so that feelings of accountability would not be aroused by the mere presence of a camera within the session. Thus, subjects watched the same purse-snatching crime, made an identification decision from the same series of photographs, and rated their confidence in that decision in either the presence or absence of videotaped self-exposure. In light of the results of Experiment 1, all subjects received an offender-present lineup.

After making an identification decision, subjects rated their confidence on a written 10-point scale. But first, half of the subjects in each condition received the following high-accountability instruction:

Now, I have one more question to ask: I want you to rate how confident you are about the identification decision you just made. I'll give you a rating scale to use. Think carefully before answering because I will then ask you to announce your rating and explain it to me. Also, I should tell you that I videotaped you looking through the photographs and making an identification decision. We'll be having students watch the tape in a class, so they can see how confident you seemed firsthand. Any questions?

Subjects in the low-accountability condition received the following instruction:

Now, I have one more question to ask: I want you to rate how confident you are about the identification decision you just made. I'll give you a rating scale to use. Don't put your name on it or identify yourself in any way; it's completely anonymous. When you're done, fold the paper and deposit it into that box on the table. Any questions?

All subjects were videotaped by a hidden camera. Those in the two RSA groups and in the high-accountability control group were later informed of the videotape (low-accountability control subjects were not told until the session was complete), but only those in the RSA condition actually watched the tape.

As an accountability manipulation check, data on two additional dependent variables were collected. First, as a rough behavioral measure of how much thought subjects devoted to their confidence ratings, the experimenter unobtrusively recorded with a stopwatch the amount

\footnotetext{
${ }^{4}$ We are indebted to Brian Cutler for this insight and the supporting rationale.

${ }^{5}$ Tetlock and $\mathrm{Kim}$ (1987) found that the beneficial effect of accountability was greater when the manipulation preceded the task on which confidence ratings were later based. In this situation, social judgments were improved, and more appropriate levels of confidence were reported. We chose to introduce the manipulation after identifications were made, however, to avoid possible effects of accountability on identification performance.
} 
of time it took subjects to circle their ratings on the written scale. Second, subjects were handed a final questionnaire in which they were asked to explain their ratings and to indicate, on a 10-point scale from not at all (1) to very (10), how carefully they had thought about their identification decisions before rating their confidence. Finally, subjects were asked for the name of a close friend on campus and for permission to show their videotape to that friend.

\section{Results}

Overall, 52 mock witnesses (80\%) made an identification, 37 accurate and 15 inaccurate. Thirteen subjects erroneously chose not to make an identification. Decisions were not significantly related to either $R S A$ or accountability manipulations, $\chi^{2} s(2$, $N=52$ ) $=2.14$ and 0.15 , respectively. To test the effectiveness of the accountability manipulation, confidence-rating response time and carefulness self-reports were analyzed in 2 (RSA, control) $\times 2$ (high, low accountability) ANOVAs. These two measures were moderately correlated, with longer response times associated with higher carefulness ratings $(r=.31, p<.02, n=$ $60) .{ }^{6}$ Results on both measures were consistent with expectations. Main effects for accountability indicated that subjects who received high-compared with low-accountability instructions took more time to rate their confidence $(M s=22.88$ and 11.83 , respectively), $F(1,56)=16.92, p<.001$, and viewed themselves as more careful in the process $(M s=7.29$ and 6.25 , respectively), $F(1,61)=3.90, p<.05$.

It is important to note that except for a nonsignificant tendency for higher carefulness ratings under RSA than control conditions $(M s=7.15$ and 6.59 , respectively), $F(1,61)=2.09$, $p<.15$, no other main effects or interactions were found with these measures. Thus, videotaped self-exposure did not, as one might predict from an accountability standpoint, lead subjects to spend more time thinking about their confidence ratings or to describe themselves as more careful in the process.

To examine variations in the correlation between accuracy and confidence, we conducted a 2 (RSA, control) $\times 2$ (high, low accountability) $\times 2$ (correct, incorrect identification decisions) ANOVA on all subjects. Because only an offender-present lineup was used, incorrect decisions consisted of a combination of false identifications and nonidentifications. This analysis yielded a main effect for accuracy, with subjects who made correct decisions generally more confident than those who made incorrect decisions ( $M \mathrm{~s}=5.64$ and 4.39 , respectively), $F(1,57)=6.94, p<.01$. When this analysis included only subjects who made a correct or incorrect identification (i.e., choosers only), the result was essentially the same $(M s=5.64$ and 3.93, respectively), $F(1,44)=5.85, p<.02$. There were no other significant main effects or interactions.

Specific comparisons within each of the four cells examined the effect more closely. As seen in Table 2, accurate subjects were more confident than those who made incorrect decisions in both high- and low-accountability RSA groups and in the high-accountability control group. Under what can be considered the standard condition (i.e., low-accountability, control), however, there was no such difference. Stated in correlational terms, the accuracy-confidence correlations in the four groups were .43 in the high-accountability RSA group $(p<.10, n=15)$, .40 in the low-accountability RSA group $(p<.15, n=14), .44$ in the high-accountability control group ( $p<.08, n=18$ ), and
Table 2

Mean Confidence Ratings of Subjects Who Made Accurate

Versus Inaccurate Identification Decisions in Experiment 2

\begin{tabular}{|c|c|c|c|c|}
\hline \multirow[b]{3}{*}{ Condition } & \multicolumn{4}{|c|}{ Identification decision } \\
\hline & \multicolumn{2}{|c|}{ Correct } & \multicolumn{2}{|c|}{ Incorrect ${ }^{\mathrm{a}}$} \\
\hline & Rating & $n$ & Rating & $n$ \\
\hline \multicolumn{5}{|l|}{ RSA } \\
\hline High $^{b}$ & 6.17 & 6 & 4.33 & 9 \\
\hline Low & 5.38 & 8 & 3.83 & 6 \\
\hline \multicolumn{5}{|l|}{ Control } \\
\hline High & 5.83 & 12 & 3.33 & 6 \\
\hline Low & 5.18 & 11 & 5.29 & 7 \\
\hline Overall & 5.64 & 37 & 4.39 & 28 \\
\hline
\end{tabular}

Note. $\mathrm{RSA}=$ retrospective self-awareness.

- This group combines those who made an incorrect identification and those who did not make an identification (i.e, choosers and nonchoosers). ${ }^{b}$ High and low refer to the accountability condition.

-.03 in the low-accountability control group ( $n s, n=18$ ). In short, RSA and accountability were both sufficient without the other to produce an accuracy-confidence correlation.

Finally, recall that 19 friends of witnesses who had made an identification watched the friend's videotape, made a judgment about accuracy, and estimated the friend's confidence. For this sample of witnesses, accuracy and confidence were highly correlated $\left(r_{\mathrm{pb}}=.53, p<.002, n=19\right)$. As to whether observers can discern a friend's level of confidence and match that estimate to accuracy by observing a videotape of the identification decision, the results were not supportive. As in Experiment 1, observer estimates of witness confidence were significantly correlated with witness self-ratings of confidence $(r=.49, p<$ $.05, n=19)$, but not with identification accuracy per se $\left(r_{\mathrm{pb}}=\right.$ $.26, p<.20, n=19$ ). Indeed, the friends could not distinguish between accurate and inaccurate witnesses by watching the identification tapes: Only 11 of 19 (57.9\%) were correct in their judgments of witness accuracy, discriminations that did not exceed chance-level performance. Finally, perceived witness accuracy and confidence were highly correlated: Observers who thought that their friends were correct also perceived them as more confident $\left(r_{\mathrm{pb}}=.69, p<.01, n=19\right)$.

\section{General Discussion}

In the context of eyewitness testimony, we sought to define the lineup conditions under which RSA increases the accuracy-confidence correlation, to examine the possible retrievalcue and self-perception mechanisms for this effect, and to test a third, accountability-based explanation. As to when RSA increases the accuracy-confidence correlation, our results replicated previous findings with an important qualification: RSA produced a significant correlation between accuracy and confidence among subjects who made correct or incorrect photographic identifications, but not among those who correctly or

\footnotetext{
${ }^{6}$ Response time was not recorded for 5 subjects, so all analyses involving this measure are based on an $n$ of 60 .
} 
incorrectly chose not to make an identification. This limit appears reliable, as Lindsay (1990) recently obtained a correlation of .53 among choosers $(n=23)$, compared with only .07 among nonchoosers $(n=39){ }^{7}$ Videotaped self-exposure thus benefits only witnesses who observe themselves actually making a choice among alternatives. Of course, these are the witnesses who create the most problems within the legal system, moving the prosecution of cases forward and testifying in front of a jury.

\section{Theoretical Implications}

On the conceptual question of why the RSA effect occurs, three possible explanations were examined. First, there was no support for the hypothesis that videotaped self-exposure serves as a retrieval cue, prompting witnesses to recall the thoughts and feelings that accompanied their prior decisions. To prompt this relatively internal focus of attention, we used an over-theshoulder camera angle that reinstated for subjects their initial perspective on the photo-identification task. Yet a significant correlation was not found in this situation. The retrieval-cue hypothesis was further tested from an individual differences perspective by comparing subjects on a dispositional measure of private self-consciousness, the tendency toward self-awareness of an introspective nature (e.g., "I'm aware of how my mind works when I work on a problem.") Again, however, there were no significant differences between those high and low in private self-consciousness in the RSA or control group. Coupled with previous failures to increase the accuracy-confidence correlation by introspection (Kassin, 1985), there is little support for the retrieval-cue hypothesis.

Derived from Bem's (1972) self-perception theory, a second possibility is that videotaped self-exposure alerts subjects to informative but previously unobserved variations in their own overt behavior. In its radical form, this hypothesis implies that videotaped feedback informs not only the actor but also outside observers. Our study offers mixed support for this view. On the supportive side, Experiment 1 indicated that only subjects high in public self-consciousness benefited from RSA, with a signifcant accuracy-confidence correlation in this condition but not in the control group. On the other hand, observers who saw identification tapes in Experiment 1 were not more accurate in their judgments than those who viewed only an examination. Even friends who viewed the tapes in Experiment 2 could not match their accuracy judgments or confidence estimates to the witness's performance. Together, these results are inconsistent with the "radical" self-perception hypothesis that all the necessary information is on the videotape and that all viewers are capable of decoding that information. Instead, the results suggest a "modified" self-perception hypothesis, one that applies only to certain witnesses and not to observers. Specifically, people who are predisposed to focus on their public behavior and appearance are uniquely sensitive to subtle cues that betray the ease or difficulty with which they made their decision. The question that remains is, what cues provide these witnesses with the necessary information?

To explore this question phenomenologically, 38 Stanford University students participated in an RSA condition and were queried about the experience. The correlation between accu- racy and confidence was $.35(p<.02, n=38)$. Among subjects who made a correct or incorrect identification, that correlation was even higher $(r=.57, p<.002, n=23)$. Asked in open-ended terms what they noticed, thought about, or were surprised about while watching the RSA tape, subjects cited the following factors, with diminishing frequency: the manner in which they had searched the photographs (i.e., the number of times and the sequence in which they looked at each photo; $n=31$ ), changes in facial expressions $(n=29)$, body movements $(n=14)$, thoughts they had while making a decision $(n=12)$, words spoken $(n=6)$, response time $(n=5)$, physical appearance $(n=4)$, and tone of voice $(n=2)$.

These interview data suggest that RSA subjects focused mostly on overt behavioral cues, not on the retrieval of thoughts that accompanied their performance. What specific cues were most helpful? Further analyses revealed an interesting pattern. By using a median split on confidence, each subject's rating was deemed high or low in the sample as a whole. Subjects were then categorized as discriminators when performance matched confidence (i.e., accurate-high confidence, inaccurate-low confidence; $n=23$ ) and nondiscriminators when it did not (i.e., accurate-low confidence, inaccurate-high confidence; $n=15$ ). When asked "How accurately do you think the videotape conveys your true level of confidence?" the discriminators provided higher ratings than nondiscriminators, $(M \mathrm{~s}=2.09$ and 1.60 , respectively, on a 3 -point scale), $t(36)=-2.40, p<.05$. More to the point, a comparison of factors cited by these groups revealed that discriminators were more likely to cite the manner in which they searched the photographs $(.29$ and .00 , respectively, $p<.05$ ) but less likely to report noticing or thinking about their own facial expressions ( 22 and .53 , respectively, $p<$ $.05)$. Apparently the photo-search process provides diagnostic information. Indeed, the total number of times all photographs were examined correlated highly with response time $(r=.71$, $p<.001, n=38$ ), and quick response times are at least modestly associated with greater accuracy (see Kassin, 1985; Sporer, 1990). This result also suggests that facial expressions are not informative, a conclusion that supports a recent study in which Turtle (1989) replicated the RSA effect not only in the standard condition, but also in one that showed witnesses only a silhouette of themselves-in other words, absent facial cues. In fact, Turtle found that observer ratings of witness confidence correlated with witness accuracy when observers saw the silhouetted RSA tapes. As in research on the detection of deception (DePaulo, Lassiter, \& Stone, 1982), this latter finding suggests that facial cues may distract observers from other, more diagnostic information. More research is needed to test the self-perception hypothesis and to isolate the behavioral cues that facilitate or inhibit the RSA effect.

Experiment 2 also tested a third, accountability hypothesis. On the basis of research in other contexts, we speculated that videotaped self-exposure, by enhancing the public nature of the

\footnotetext{
${ }^{7}$ In an interesting variation on the RSA procedure, R. C. L. Lindsay (personal communication, 1990) also had witnesses rate their confidence, watch their identification, and then rate confidence a second time. Perhaps because of commitment effects, these subjects did not exhibit an increase in the accuracy-confidence correlation.
} 
task, leads subject witnesses to become more motivated to think carefully about their confidence reports. As such, RSA and accountability were independently varied in the same experiment. There were two key results. First, high accountability alone (i.e., without RSA) increased the accuracy-confidence correlation, even though the instruction followed rather than preceded the identification, a relatively weak manipulation (Tetlock \& Kim, 1987). Compared with those in the low-accountability condition, high-accountability subjects spent more time thinking about their confidence and said they were more careful in the process. The second key result is that the RSA effect occurred in a low-accountability situation in which witnesses thought their confidence ratings were anonymous. In this group, accuracy and confidence were correlated even though the subjects spent less time on their confidence ratings and did not describe themselves as particularly careful in the process. This pattern compels the following new conclusions: (a) Heightened accountability is sufficient to produce a correlation between accuracy and confidence, but (b) accountability concerns are not a necessary precondition for the RSA effect to occur, and hence they cannot be used to explain the phenomenon.

These latter results provide indirect support for a modified self-perception hypothesis. To heighten accountability, subjects were told that they would announce their confidence ratings aloud for subsequent observation by others. Although we do not know what the subjects in this condition were thinking (e.g., whether they reflected on mental processes or focused on overt behavioral cues), self-awareness research in other contexts indicates that cameras and audiences evoke a state of public selfawareness that, like the trait of public self-consciousness, leads people to focus on the self as a social object as viewed by others (introspective or private awareness is induced by mirrors; Buss, 1980; Carver \& Scheier, 1987). In short, accuracy and confidence may well be correlated whenever witnesses are in a state of public self-awareness while reporting confidence, a state brought about by either videotaped self-exposure or heightened accountability.

Experiment 2 also contributes to the growing literature on the corrective benefits of accountability. That is, just as high accountability reduces primacy effects (Tetlock, 1983), the fundamental attribution error (Tetlock, 1985), and overconfidence (Tetlock \& Kim, 1987) in judgments made of others, it also elicits confidence estimates predictive of accuracy in the context of self-perception as well. The reason? The fact that manipulations of accountability closely resemble those used to arouse public self-awareness raises the possibility that these constructs are functionally equivalent. Through accountability manipulation checks, we found that RSA did not increase the amount of time subjects took to rate confidence or how careful they were in the process. The benefits of RSA are thus derived not from a heightened motivation for accurate self-report but from access to information about the self that was not otherwise salient or accessible to awareness. Unfortunately, we did not test the effects of accountability instructions on public self-focus (e.g., as measured by perspective taking; see Hass, 1984). Further research should examine the hypothesis that the benefits of accountability are derived, at least in part, by leading subjects to become publicly self-aware (see Tetlock, Skitka, \& Boettger, 1989).

Finally, the effects of RSA may extend beyond the eyewitness accuracy-confidence correlation. Paralleling the accountability literature, for example, videotaped self-exposure might also be expected to mitigate primacy, overattribution, and other biases. If the weak accuracy-confidence correlation is a special instance of the generally tenuous link between subjective selfreports and behavior, as described by Nisbett and Wilson (1977), RSA may also increase the accuracy of self-report in a way that introspection manipulations (e.g., the instruction to "analyze why you feel the way you do"; Wilson \& Schooler, 1991) cannot. In a recently completed test of this hypothesis, Barndollar (1991) had subjects complete a packet of embeddedfigures items as quickly as they could and then rate the difficulty of the task. Using task completion time as an objective, behavioral index of difficulty, she found that the correlation between subjective ratings and behavior was highly significant among subjects who had watched themselves on videotape before making their ratings, but not among those in a no-videotape control group. Thus, perhaps even Nisbett and Wilson's subjects would have accurately reported the causes of their behavior had they first viewed a tape of their own experimental sessions.

\section{Forensic Implications}

From a forensic standpoint, the studies reported here corroborate the finding that jurors cannot discriminate between accurate and inaccurate witnesses (Brigham \& Bothwell, 1983; Cutler et al., 1988; Lindsay et al, 1989; Wells et al., 1979). Clearly, exposure to identification tapes, whether by strangers or friends of the witness, did not improve matters. As to whether such tapes could have practical utility, however, three points are worth noting.

First, following a suggestion made earlier (Kassin, 1985), perhaps identification videotapes should be introduced into evidence in the hope that they might have a direct effect on juror evaluations of eyewitness testimony. In other words, perhaps jurors would improve their ability to make discriminations by watching the videotapes in addition to the witness examinations. Our results do not support this proposal. The videotapes lowered observers' ratings of witness confidence, but they did not increase the accuracy of their judgments. Somewhat more encouraging data were reported by Turtle (1989), who found that mock juror accuracy was increased, though not significantly, from $47 \%$ among those who watched the witness's examination to $61 \%$ among those who saw the identification videotapes (subjects who saw both exhibited a $56 \%$ rate of accuracy).

A second possibility would be to show identification tapes to the witnesses in the hope that they would be in a better position to evaluate themselves before prompting an investigation of the case and later testifying in front of a jury. It stands to reason that (a) because RSA increases the accuracy-confidence correlation for witnesses who choose to make an identification and (b) because a witness's confidence influences others' judgments of accuracy (e.g., police investigators, prosecutors, judges, and juries), then (c) RSA should improve the decisions made about the 
quality of identification evidence. Experiment 1 did not adequately test this hypothesis, inasmuch as witnesses were examined before the RSA manipulation and could not have been influenced by the experience while testifying. Turtle (1989) did have observers watch the testimony of witnesses who had already seen their performance on videotape. As in our experiment, however, his observers showed no improvement in their judgments. Thus, we are equally skeptical about the usefulness of making identification tapes available to witnesses prior to their entry into the courtroom.

Finally, the accountability data call into question whether the low-accuracy-confidence correlations found in the laboratory generalize to real-world settings naturally characterized by high levels of witness accountability and hence whether RSA is a necessary intervention. Knowing that an identification will mean real consequences for themselves and for the accused, eyewitnesses brought into police stations, lawyers offices, and courtrooms may think more critically about the task, their own performance, and their own level of certainty. At this point, available research does not clearly support or refute this implication. Murray and Wells (1982) found that the accuracy-confidence correlation was lower when witnesses thought the crime was real than when they knew they were participants in a psychology experiment. Sanders and Warnick (1981) found that confidence was not affected by perceived consequences. And the accuracy-confidence correlation is highly significant in some field studies (Brigham, Maass, Snyder, \& Spaulding, 1982) but not in others (Malpass \& Devine, 1981). Further research is thus needed to evaluate the role of accountability in a more serious and realistic setting.

\section{References}

Barndollar, K. A. (1991). Retrospective self-awareness and the accuracy-confidence correlation in eyewitness testimony: Toward a theory of self-insight. Unpublished senior honor's thesis, Williams College, Williamstown, MA.

Bell, B. E., \& Loftus, E. F. (1989). Trivial persuasion in the courtroom: The power of (a few) minor details. Journal of Personality and Social Psychology, 56, 669-679.

Bem, D. J. (1972). Self-perception theory. In L. Berkowitz (Ed.), $A d$ vances in experimental social psychology (Vol. 6, pp. 1-62). San Diego, CA: Academic Press.

Bothwell, R. K., Deffenbacher, K. A., \& Brigham, J. C. (1987). Correlation of eyewitness _.ccuracy and confidence: Optimality hypothesis revisited. Journal of Applied Psychology, 72, 691-695.

Brigham, J. C., \& Bothwell, R. K. (1983). The ability of prospective jurors to estimate the accuracy of eyewitness identification. Law and Human Behavior, 7, 19-30.

Brigham, J. C., Maass, A., Snyder, L. D., \& Spaulding, K. (1982). Accuracy of eyewitness identifications in a field setting. Journal of Personality and Social Psychology, 42, 673-681.

Brigham, J. C., \& Wolfskiel, M. P. (1983). Opinions of attorneys and law enforcement personnel on the accuracy of eyewitness identification. Law and Human Behavior, 7, 337-349.

Buss, A. H. (1980). Self-consciousness and social anxiety. San Francisco: Freeman.

Cacioppo, J. T., \& Petty, R. E. (1982). The need for cognition. Journal of Personality and Social Psychology, 42, 116-131.

Carver, C. S., \& Scheier, M. F. (1987). The blind men and the elephant:
Selective examination of the public-private literature gives rise to a faulty perception. Journal of Personality, 55, 525-541.

Cutler, B. L., \& Penrod, S. D. (1988). Improving the reliability of eyewitness identification: Lineup construction and presentation. Journal of Applied Psychology, 73, 281-290.

Cutler, B. L., Penrod, S. D., \& Dexter, H. R. (1989). The eyewitness, the expert psychologist, and the jury. Law and Human Behavior, 13 , 311-332.

Cutler, B. L., Penrod, S. D., \& Martens, T. K. (1987). The reliability of eyewitness identification: The role of system and estimator variables. Law and Human Behavior, 11, 233-258.

Cutler, B. L., Penrod, S. D., \& Stuve, T. E. (1988). Jury decision-making in eyewitness identification cases. Law and Human Behavior, 12, $41-56$.

Deffenbacher, K. A., \& Loftus, E. F. (1982). Do jurors share a common understanding concerning eyewitness behavior? Law and Human Behavior, 6, 15-30.

DePaulo, B. M., Lassiter, G. D., \& Stone, J. I. (1982). Attentional determinants of success at detecting deception and truth. Personality and Social Psychology Bulletin, 8, 273-279.

Dunning, D., Griffin, D. W., Milojkovic, J. D., \& Ross, L. (1990). The overconfidence effect in social prediction. Journal of Personality and Social Psychology, 58, 568-581.

Fenigstein, A., Scheier, M. F., \& Buss, A. H. (1975). Public and private self-consciousness: Assessment and theory. Journal of Consulting and Clinical Psychology, 43, 522-527.

Fleet, M. L., Brigham, J. C., \& Bothwell, R. K. (1987). The confidenceaccuracy relationship: The effects of confidence assessment and choosing. Journal of Applied Social Psychology, 17, 171-187.

Funder, D. C., \& Colvin, C. R. (1988). Friends and strangers: Acquaintanceship, agreement, and the accuracy of personality judgment. Journal of Personality and Social Psychology, 55, 149-158.

Hass, R. G. (1984). Perspective taking and self-awareness: Drawing an E on your forehead. Journal of Personality and Social Psychology, 46, 788-798.

Kassin, S. M. (1985). Eyewitness identification: Retrospective selfawareness and the accuracy-confidence correlation. Journal of Personality and Social Psycholog., 49, 878-893.

Kassin, S. M., Ellsworth, P. C., \& Smith, V. L. (1989). The "general acceptance" of psychological research on eyewitness testimony: A survey of the experts. American Psychologist, 44, 1089-1098.

Lindsay, R. C. L., \& Wells, G. L. (1985). Improving eyewitness identifications: Simultaneous versus sequential lineup presentation. Journal of Applied Psychology, 70, 556-574.

Lindsay, R. C. L., Wells, G. L., \& O'Connor, F. J. (1989). Mock-juror belief of accurate and inaccurate eyewitnesses. Law and Human Behavior, 13, 333-339.

Lindsay, R. C. L., Wells, G. L., \& Rumpel, C. M. (1981). Can people detect eyewitness identification accuracy within and across situations? Journal of Applied Psychology, 66, 79-89.

Malpass, R. S., \& Devine, P. G. (1981). Eyewitness identification: Lineup instructions and the absence of the offender. Journal of $A p$ plied Psychology, 66, 482-489.

Malpass, R. S., \& Devine, P. G. (1984). Research on suggestion in lineups and photospreads. In G. Wells \& E. Loftus (Eds), Eyewitness testimony: Psychological perspectives (pp. 64-91). Cambridge, England: Cambridge University Press.

Manson v. Brathwaite, 432 U.S. 98 (1977).

Melara, R. D., DeWitt-Rickards, T. S., \& O'Brien, T. P. (1989). Enhancing lineup identification accuracy: Two codes are better than one. Journal of Applied Psychology, 74, 706-713.

Murray, D. M., \& Wells, G. L. (1982). Does knowledge that a crime was 
staged affect eyewitness accuracy? Journal of Applied Social Psychology, 12, 42-53.

Neil v. Biggers, 409 U.S. 188 (1972).

Nisbett, R. E., \& Wilson, T. D. (1977). Telling more than we can know: Verbal reports on mental processes. Psychological Review, 84, 231259.

San Jers, G. S., \& Warnick, D. H. (1981). Truth and consequences: The effect of responsibility on eyewitness behavior. Basic and Applied Social Psychology, 2, 67-79.

Sharp, G. L., Cutler, B. L., \& Penrod, S. D. (1988). Performance feedback improves the resolution of confidence judgments. Organizational Behavior and Human Decision Processes, 42, 271-283.

Smith, V. L., Kassin, S. M., \& Ellsworth, P. C. (1989). Eyewitness accuracy and confidence: Within- versus between-subject correlations. Journal of Applied Psychology, 74, 356-359.

Snyder, M., \& Gangestad, S. (1986). On the nature of self-monitoring: Matters of assessment, matters of validity. Joumal of Personality and Social Psychology, 51, 125-131.

Sporer, S. L. (1990, March). Dissecting a witness's choice: Decision-times as predictors of eyewitness identification decisions in simultaneous and sequential lineups. Paper presented at the meeting of the American Psychology-Law Society, Williamsburg, VA.

Tetlock, P. E. (1983). Accountability and the perseverance of first impressions. Social Psychology Quarterly, 46, 285-292.

Tetlock, P. E. (1985). Accountability: A social check on the fundamental attribution error. Social Psychology Quarterly 48, 227-236.

Tetlock, P. E., \& Kim, J. I. (1987). Accountability and judgment processes in a personality prediction task. Journal of Personality and Social Psychology, 52, 700-709.

Tetlock, P. E., Skitka, L., \& Boettger, R. (1989). Social and cognitive strategies for coping with accountability: Conformity, complexity, and bolstering. Journal of Personality and Social Psychology, 57, $632-640$
Turtle, J. W. (1989). Videotaped eyewitness lineup behavior: How does it improve witnesses' confidence-accuracy correlation and can it improve jurors' identification-accuracy assessment? Unpublished manuscript, University of British Columbia, Vancouver, British Columbia, Canada.

Wells, G. L. (1978). Applied eyewitness-testimony research: System variables and estimator variables. Journal of Personality and Social Psychology, 36, 1546-1557.

Wells, G. L., \& Leippe, M. R. (1981). How do triers of fact infer the accuracy of eyewitness identifications? Memory for peripheral details can be misleading. Journal of Applied Psychology, 66, 688-696.

Wells, G. L., \& Lindsay, R. C. L. (1985). Methodological notes on the accuracy-confidence relation in eyewitness identifications. Journal of Applied Psychology. 70, 413-419.

Wells, G. L., Lindsay, R. C. L., \& Ferguson, T. J. (1979). Accuracy, confidence, and juror perceptions in eyewitness identification. Journal of Applied Psychology, 64, 440-448.

Wells, G. L., \& Murray, D. M. (1984). Eyewitness confidence. In G. Wells \& E. Loftus (Eds.), Eyewitness testimony: Psychological perspectives (pp. 155-170). Cambridge, England: Cambridge University Press.

Wilson, T. D., \& Schooler, J. W. (1991). Thinking too much: Introspection can reduce the quality of preferences and decisions. Journal of Personality and Social Psychology, 60, 181-192.

Yarmey, A. D., \& Jones, H. P. T. (1983). Is the psychology of eyewitness identification a matter of common sense? In S. Lloyd-Bostock \& B. R. Clifford (Eds.), Evaluating witness evidence (pp. 13-40). New York: Wiley.

Received June 4, 1990

Revision received November 29, 1990

Accepted May 21, 1991 